\title{
BMJ
}

\section{Long term risk for hypertension, renal impairment, and cardiovascular disease after gastroenteritis from drinking water contaminated with Escherichia coli 0157:H7: a prospective cohort study}

William FClark, professor of nephrology, 1,2 Jessica M Sontrop, assistant professor of epidemiology, 1,2,3 Jennife J Macnab, assistant professor of epidemiology, ${ }^{3}$ Marina Salvadori, associate professor of infectious disease, ${ }^{4}$ Louise Moist, associate professor of nephrology and epidemiology, ${ }^{1,2,3}$ Rita Suri, assistant professor of nephrology, ${ }^{1,2}$ Amit X Garg, associate professor of nephrology and epidemiology ${ }^{1,2,3}$

${ }^{1}$ Division of Nephrology,

Department of Medicine, London Health Sciences Centre, London, ON, Canada

${ }^{2}$ London Kidney Clinical Research Unit, London Health Sciences Centre, London, ON

${ }^{3}$ Department of Epidemiology and Biostatistics, University of Western Ontario, London, ON

${ }^{4}$ Department of Pediatric Infectious Diseases, Children's Hospital, London Health Sciences Centre, London, ON

Correspondence to: W F Clark, A2343 Westminster Tower, Victoria Hospital, 800 Commissioner's

Road East, London, ON, Canada N6A 4G5 William.Clark@lhsc.on.ca

Cite this as: BMJ 2010;341:c6020 doi:10.1136/bmj.c6020

\section{ABSTRACT}

Objectives To evaluate the risk for hypertension, renal impairment, and cardiovascular disease within eight years of gastroenteritis from drinking water contaminated with Escherichia coli 0157:H7 and Campylobacter.

Design A prospective cohort study.

Setting Walkerton, Ontario, Canada.

Participants 1977 adult participants in the Walkerton Health Study recruited between 2002 and 2005 after an outbreak of gastroenteritis in May 2000, when a municipal water system was contaminated, with no preoutbreak history of outcome measures.

Outcome measures Information was collected annually via survey, physical examination, and laboratory assessment. Primary measures were acute gastroenteritis (diarrhoeal illness lasting >3 days, bloody diarrhoea, or >3 loose stools/day), hypertension (blood pressure $\geq 140$ / $90 \mathrm{~mm} \mathrm{Hg}$ ), and renal impairment (microalbuminuria or estimated glomerular filtration rate $<60 \mathrm{ml} / \mathrm{min} / 1.73 \mathrm{~m}^{2}$ ). Self reported physician diagnosis of cardiovascular disease (myocardial infarction, stroke, or congestive heart failure) was a secondary outcome.

Results Acute gastroenteritis at the time of the outbreak was reported by 1067 (54\%) of participants. Incident hypertension was detected in 697 (35\%) (294 (32\%) of group not exposed to acute gastroenteritis v 403 (38\%) of exposed group). While 572 (29\%) had at least one indicator of renal impairment (266 (29\%) of unexposed $v$ 306 (29\%) of exposed), only 30 (1.5\%) had both (8 (0.9\%) of unexposed $v 22$ (2.1\%) of exposed). Cardiovascular disease was reported by $33 / 1749$ (1.9\%). The adjusted hazard ratios for hypertension and cardiovascular disease after acute gastroenteritis were 1.33 (95\% confidence interval 1.14 to 1.54 ) and 2.13 (1.03 to 4.43) respectively. The adjusted hazard ratio for the presence of either indicator of renal impairment was 1.15 (0.97 to 1.35) and was 3.41 (1.51 to 7.71) for the presence of both.
Conclusion Gastroenteritis from drinking water contaminated with E coli 0157:H7 and Campylobacter was associated with an increased risk for hypertension, renal impairment, and self reported cardiovascular disease. Annual monitoring of blood pressure and periodic monitoring of renal function may be warranted for individuals who experience $E$ coli $0157: \mathrm{H} 7$ gastroenteritis.

\section{INTRODUCTION}

Since the emergence of Escherichia coli O157:H7 in $1982,{ }^{1}$ outbreaks attributed to this pathogen have occurred with increasing frequency and are now documented worldwide, in developed and developing countries..$^{2-11}$ The Centers for Disease Control and Prevention estimate that $E$ coli $\mathrm{O} 157: \mathrm{H} 7$ infections cause between 50000 and 120000 gastroenteric illnesses annually in the US, resulting in over 2000 hospitalisations and 60 deaths. ${ }^{612}{ }^{13}$ Receptors for $E$ coli O157:H7 Shiga toxins reside in the kidney, and exposure can cause both renal and vascular injury resulting in haemolytic-uraemic syndrome, ${ }^{14}$ but also a subtle nephron loss ${ }^{15}$ and systemic endothelial dysfunction, ${ }^{16}$ a key variable in the pathogenesis of cardiovascular disease. ${ }^{1718}$ Subsequent renal hyperfiltration may lead to long term systemic hypertension and renal impairment. ${ }^{15}$ Although the long term health effects of $E$ coli O157:H7 infection in children resulting in haemolyticuraemic syndrome are well documented, ${ }^{19}$ the long term sequelae of milder exposure in adults are largely unknown because of the difficulty of studying a wide geographical dispersal of people who are unlikely to seek medical attention for self limited gastro enteritis. ${ }^{72021}$

In May 2000 the municipal water system in Walkerton, Ontario (Canada) became contaminated with $E$ coli O157:H7 and Campylobacter spp. At the time of the outbreak, heavy rainfall contributed to the transport of livestock faecal matter into inadequately chlorinated drinking water, supplied from a shallow well. ${ }^{22}$ 
The result was an excess of 2300 cases of gastrointestinal illness, more than 750 emergency room visits, 65 hospital admissions, 27 recognised cases of haemolytic-uraemic syndrome, and seven deaths. The low incidence of haemolytic-uraemic syndrome (a time limited disease requiring a laboratory diagnosis) relative to the number of gastroenteritis cases and high mortality are in keeping with concerns about the limited capacity of medical resources in any small rural community to respond to the sudden onset of an epidemic. Concerns about the potential for progressive subclinical disease (most of those affected had no laboratory testing during the epidemic) led to the creation of the Walkerton Health Study in 2002 to study long term health effects attributable to the water contamination. Four years after the outbreak, a 28\% increased risk for hypertension was observed among adults who developed acute gastroenteritis compared with those who were asymptomatic during the outbreak. ${ }^{23}$ The completion of the Walkerton Health Study (2002-8) provides the opportunity to analyse the long term risk for hypertension and renal impairment after gastroenteritis from drinking water contaminated with $E$ coli O157:H7 and Campylobacter. Self reported cardiovascular disease was evaluated as a secondary outcome. In addition, trends over time and potential bias from loss to follow-up are assessed.

\section{METHODS}

\section{Study design and cohort definition}

The Walkerton Health Study (2002-8, Canada) is a prospective community based cohort study with retrospective inception. Participants provided written, informed consent, and ethical approval was obtained from the University of Western Ontario's Research Ethics Board for Health Sciences.

\section{Data collection and measures}

Additional methodological details are provided elsewhere. ${ }^{23-25}$ Briefly, at study entry, participants completed a baseline questionnaire that included questions on demographics, exposure and illness at the time of the outbreak, prior medical history (including hypertension, kidney disease, cardiovascular disease, diabetes, and chronic gastrointestinal illness), past and current medications, family history, and risk factors. To assist in the identification of pre-existing disease and to collect evidence on severity of exposure, consent was obtained from $96 \%$ of participants for an audit of laboratory data and medical charts. ${ }^{25}$

In addition, participants completed annual, computer assisted personal interviews, which included questions on conditions diagnosed by a health professional, including diabetes and hypertension. Beginning in 2003, participants were asked to report the date of any physician diagnosed cardiovascular disease. Questionnaire development was guided by the US Third National Health and Nutrition Survey (NHANES III) and Statistics Canada's National Population Health Survey.
Trained study personnel measured each participant's height, weight, and blood pressure using standardised protocols at each annual visit. One manual and two automated blood pressure readings, separated by one minute, were taken of seated participants with arm resting, palm upward, using a cuff size appropriate for arm circumference. ${ }^{26}$ The automated readings were taken with a calibrated oscillometric device (Dinamap Pro 100 or 1846SX units, GE Medical Systems Information Technologies, Tampa FL, USA). Participants were asked to refrain from smoking 30 minutes before the measurements. Serum creatinine concentration was measured annually, as was random (spot) urine analysis for albumin:creatinine ratio. Additional testing varied by study year to reduce respondent burden; these included fasting serum glucose, oral glucose tolerance testing (when indicated), and 24 hour urine collection. Estimated glomerular filtration rate was calculated using the abbreviated modification of diet in renal disease equation. ${ }^{27}$

\section{Definitions \\ Exposure}

Because of the overwhelming demand on the medical system at the time of the outbreak, stool cultures were not routinely collected once the source of the water contamination had been identified, and so we could not use the results for defining exposure. We therefore defined acute gastroenteritis using a similar, but more stringent case definition than that used by the original outbreak team. The exposed group included those who reported diarrhoeal illness lasting $>3$ days, or diarrhoea with $>3$ loose stools/day, or any amount of bloody diarrhoea. When possible, self reported symptoms were confirmed by checking the participant's medical records. ${ }^{25}$ Assessment methods did not differ between exposure groups.

\section{Outcomes}

Hypertension was diagnosed if the mean of three blood pressure measurements was $\geq 140 / 90 \mathrm{~mm} \mathrm{Hg}$ at any follow-up visit or if treatment for hypertension was reported. In the presence of diabetes or kidney disease, hypertension was defined as blood pressure $\geq 130$ / $80 \mathrm{~mm} \mathrm{Hg} .{ }^{26}$

Structural and functional renal impairment were defined as microalbuminuria (albumin:creatinine ratio $>2.0 \mathrm{mg} / \mathrm{mmol}$ in men and $>2.8 \mathrm{mg} / \mathrm{mmol}$ in women) and estimated glomerular filtration rate $<60 \mathrm{ml} / \mathrm{min} / 1.73 \mathrm{~m}^{2}$, respectively. ${ }^{2829}$ Two classifications of renal impairment were analysed: the presence of either indicator of renal impairment and the presence of both indicators.

Cardiovascular disease was defined as a self reported physician diagnosis of heart attack, stroke, or congestive heart failure based on the question format used in NHANES III. Participants who left the study because of death from heart attack or stroke were also included in this composite outcome. 


\section{Other variables}

Diabetes was defined as the presence of fasting plasma glucose concentration $\geq 7.0 \mathrm{mmol} / \mathrm{l}$, random plasma glucose concentration or at two hours after an oral glucose tolerance test $\geq 11.1 \mathrm{mmol} / 1$, a medical diagnosis of diabetes, or the use of oral hypoglycaemic agents or insulin. ${ }^{30}$

Attrition - To assess potential bias from loss to follow-up, participants were grouped according to response pattern. "Committed responders" attended all assessments after entering the study, "intermittent responders" missed at least one assessment, and "leavers" completed only one assessment.

\section{Eligibility and exclusions}

Residents of Walkerton and the surrounding areas were invited to participate in the long term follow-up by attending an annual clinic regardless of whether they drank the contaminated water during the outbreak of gastroenteritis in May 2000. We excluded participants who developed haemolytic-uraemic syndrome during the outbreak, who were $\leq 17$ years old at study entry, and those who joined the study for the first time after 2005, since the accuracy of symptom recall was expected to decrease over time (fig 1). To assess the risk for hypertension, renal impairment, and cardiovascular disease (myocardial infarction, stroke, or congestive heart failure), we excluded participants with evidence of these conditions before the outbreak (fig 1).

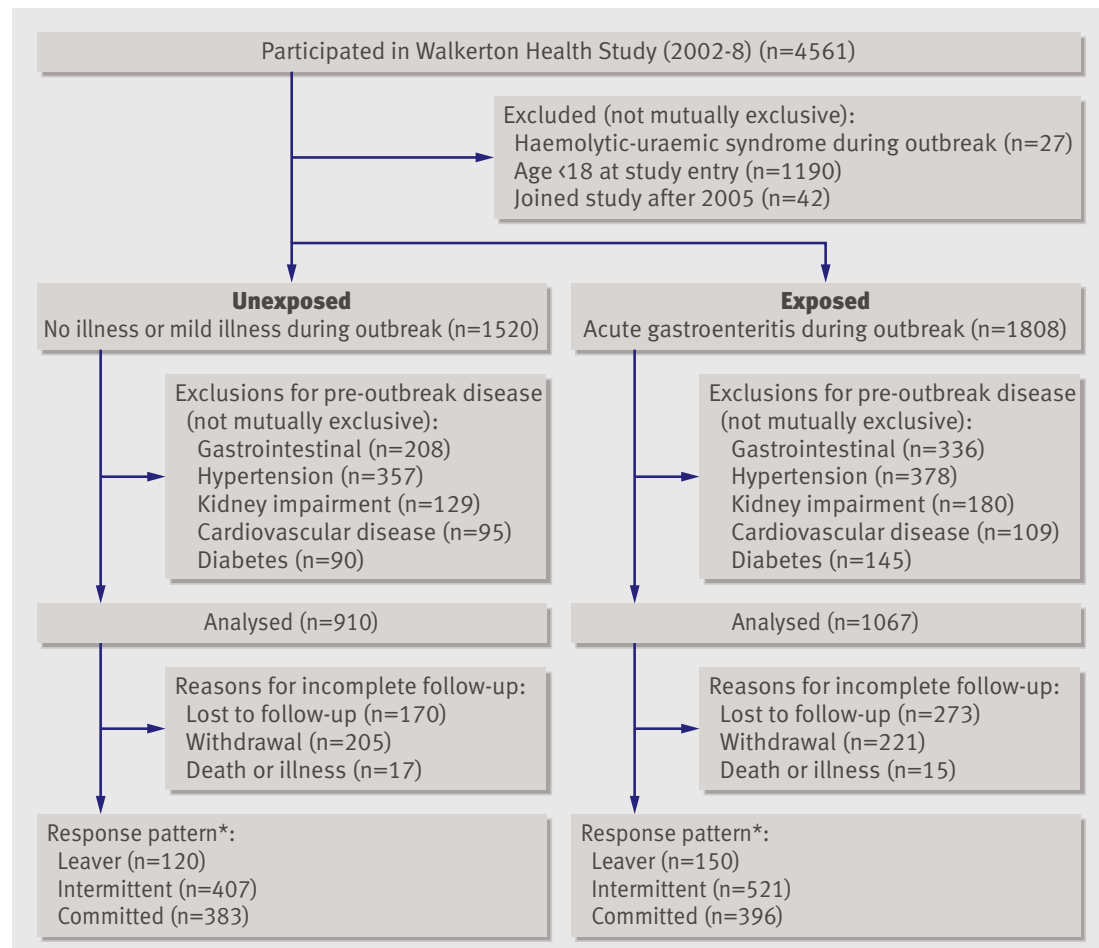

*Leaver $=$ completed only one follow-up assessment. Intermittent = missed at least one assessment. Committed $=$ attended all assessments after study entry.

\section{Statistical analysis}

We used Cox regression models to estimate hazard ratios for incident hypertension, renal impairment, and cardiovascular disease. The "time to event" variables were calculated as time from the outbreak of gastroenteritis (15 May 2000) to time of first diagnosis with hypertension, renal impairment, or cardiovascular disease. Participants who did not develop the outcome were censored at the time of their last follow-up visit.

We checked the assumption of proportionality for each covariate using the time interaction and Schoenfeld residual tests. ${ }^{31}$ The initial model for renal impairment did not meet the proportionality assumption, and we used an extended Cox regression model with age included as a time dependent covariate for this analysis. ${ }^{31}$ Four cases with missing data for the outcome of renal impairment were excluded from the analysis.

Participants who experienced no illness or only mild illness at the time of the outbreak served as the reference group for all analyses. Age (in one year increments) and sex were included in all models.

Possible confounders considered for statistical adjustment included risk factors for hypertension, kidney disease, and cardiovascular disease; diabetes; obesity at study entry (body mass index $\geq 30$, data missing for two); tobacco smoking (missing for eight); and family history of kidney disease (missing for three), hypertension (missing for 12), or diabetes (missing for three). Health assessment in the year before the outbreak (missing for 27) was included to adjust for possible imbalances in health seeking behaviour, which may have resulted in residual confounding due to misclassification of exposure or risk factors.

Information on covariates was collected from multiple sources, and, in the absence of any evidence, missing data on risk factors were set to zero, which produced similar or more conservative results than a complete case analysis. Models were reduced using backward elimination at $\alpha=0.15^{3233}$ unless elimination changed the exposure-outcome association by $>5 \%$. $^{33} 34$

\section{Supplementary analyses}

To ensure the outcome was truly a measure of incidence, we excluded participants diagnosed with hypertension or renal impairment at study entry. To assess the impact of recall bias on exposure classification, we conducted sensitivity analyses for those whose self reported gastroenteritis was confirmed by an audit of medical records. To assist in describing the potential impact of bias from loss to follow-up, effect modification by response pattern was examined by testing the interaction of response pattern by main effect, and the change in risk was examined when the number of follow up assessments was entered into the model.

\section{RESULTS}

\section{Sample description}

A total of 4561 residents from Walkerton and the surrounding area joined the study between March 2002 and August 2008. Previous analyses established that 
Table 1| Personal, exposure related, and health related characteristics of 1977 participants in Walkerton Health Study in relation to self reported exposure to acute gastroenteritis. Values are numbers (percentages) of participants unless stated otherwise

\begin{tabular}{|c|c|c|}
\hline Characteristics & $\begin{array}{l}\text { No or only mild illness } \\
\qquad(n=910)\end{array}$ & $\begin{array}{l}\text { Acute gastroenteritis } \\
\qquad(n=1067)\end{array}$ \\
\hline \multicolumn{3}{|l|}{ Personal } \\
\hline Female & $529(58.1)$ & $598(56.0)$ \\
\hline Mean (SD) age at study entry (years) & $43.1(15.6)$ & $40.4(14.4)$ \\
\hline White ethnicity & $896(98.5)$ & $1051(98.5)$ \\
\hline Lived in Walkerton area during outbreak & $625(68.7)$ & $738(69.2)$ \\
\hline \multicolumn{3}{|l|}{ Exposure related } \\
\hline Drank contaminated water & $892(98.0)$ & $1063(99.6)$ \\
\hline Self reported illness of any nature* & $234(25.7)$ & $1067(100)$ \\
\hline Abdominal cramps & $172(18.9)$ & $979(91.8)$ \\
\hline Fever & $47(5.2)$ & $445(41.7)$ \\
\hline Bloody diarrhoea & 0 & $310(29.1)$ \\
\hline$>3$ loose stools/day & 0 & $910(85.3)$ \\
\hline \multicolumn{3}{|l|}{ No of days with diarrhoea: } \\
\hline$\leq 1$ & $50(5.5)$ & $46(4.3)$ \\
\hline $2-3$ & $77(8.5)$ & $247(23.1)$ \\
\hline $4-5$ & 0 & $223(20.9)$ \\
\hline$\geq 6$ & 0 & $547(51.3)$ \\
\hline Stool culture performed†: & $8(0.9)$ & $123(11.5)$ \\
\hline Positive for E coli 0157:H7 & 2/131 (1.5) & 23/131 (17.6) \\
\hline Positive for Campylobacter & $1 / 131(0.8)$ & 24/131 (18.3) \\
\hline Positive for both & 0 & 2/131 (1.5) \\
\hline Gastroenteritis confirmed from medical records $\ddagger$ & $45 / 725(6.2)$ & $333 / 900(37.0)$ \\
\hline \multicolumn{3}{|l|}{ Health related } \\
\hline Obese at study entry & $228(25.1)$ & $332(31.1)$ \\
\hline Diabetes & $26(2.9)$ & $47(4.4)$ \\
\hline Family history of kidney failure & $16(1.8)$ & $22(2.1)$ \\
\hline Family history of hypertension & $339(37.3)$ & $432(40.5)$ \\
\hline Family history of diabetes & $212(23.3)$ & $241(22.6)$ \\
\hline Medical check-up in year before outbreak & $587(65.6)$ & $640(60.7)$ \\
\hline Previous deep vein thrombosis & $20(2.2)$ & $14(1.3)$ \\
\hline Previous elevated cholesterol & $92(10.1)$ & $87(8.2)$ \\
\hline Tobacco smoking & $319(35.1)$ & $426(39.9)$ \\
\hline
\end{tabular}

*Symptoms were recalled by participants at least 2 years after outbreak.

†Positive culture results are reported as a percentage of all stool cultures performed $(n=131(8+123))$. $\ddagger$ Medical records data were abstracted for $82 \%$ of participants.

our study cohort was representative of the target population. ${ }^{24}$ After exclusions for pre-outbreak disease (fig 1), 1977 adults with at least one assessment were available for analysis. Most of the participants (1677, $85 \%)$ joined the study in 2002. Overall, $779(39 \%)$ completed all assessments after study entry, 928 $(47 \%)$ missed at least one follow-up visit, and 270 $(14 \%)$ left the study after one assessment. The main reasons for incomplete follow-up were loss to follow-up $(443 / 901(49 \%))$ and participant withdrawal from the study (426/901 (47\%)). Participants who left the study were encouraged to re-enter at any time after missing an assessment. Permanent study exit, although slightly higher in the first year $(227(12 \%))$, ranged between 108 $(5.5 \%)$ and $163(8.2 \%)$ thereafter. Median follow-up time from the outbreak was 7.9 years (interquartile range 4.9-8.0), and five years of follow-up information from the time of the outbreak was available for 1442 (73\%) of the cohort.
Acute gastroenteritis after drinking contaminated water Of the 1977 adult participants, 1957 (99\%) reported drinking the contaminated municipal water, 910 $(46 \%)$ had no illness or only mild illness at the time of the outbreak, and 1067 (54\%) met the criteria for acute gastroenteritis (of whom 378 sought medical attention). Among the 910 participants who did not meet the criteria for acute gastroenteritis (diarrhoea lasting $>3$ days, diarrhoea with $>3$ loose stools a day, or any amount of bloody diarrhoea), 777 (85\%) reported no diarrhoeal illness and 133 (15\%) had mild diarrhoeal illness ( $<3$ loose stools/day for fewer than 3 days and no bloody diarrhoea). Of the 131 stool samples tested for pathogens, 19\% were positive for $E$ coli O157:H7, 19\% were positive for Campylobacter, and 1.5\% showed coinfection.

Those exposed to acute gastroenteritis at the time of the outbreak were more likely to be obese $(\mathrm{P}=0.001)$, tobacco smokers $(\mathrm{P}=0.03)$, and were less likely to have had a medical check up in the year before the outbreak $(\mathrm{P}=0.03)$ (table 1). The group not exposed to acute gastroenteritis received slightly more assessments than the exposed group, although the difference was not statistically significant (mean number of assessments 4.8 v. 4.6, $\mathrm{P}=0.08$ ). In all analyses, defining exposure based on confirmation from health records did not substantively change effect sizes, although confidence intervals became wider.

\section{Risk of hypertension}

Fig 2 shows the post-outbreak incidence of hypertension, adjusted for age and sex, in the two groups of participants. The multivariate adjusted hazard ratio for hypertension after acute gastroenteritis was 1.33 (95\% confidence interval 1.14 to 1.54 ) (table 2), which increased to 1.47 (1.17 to 1.86) after excluding participants diagnosed with hypertension at study entry. The hazard ratio did not change after controlling for number of assessments and did not vary significantly with response pattern $(\mathrm{P}=0.45)$. The adjusted hazard ratio decreased slightly over time, from 1.48 (1.04 to 2.09) during the first two years after the outbreak to 1.25 (0.78 to 1.99 ) in the sixth to eighth years after the outbreak, although the interaction with time was not statistically significant $(\mathrm{P}=0.84)$.

\section{Risk of renal impairment}

Incident microalbuminuria was detected in 405 participants $(180(20 \%)$ of the unexposed group and 225 $(21 \%)$ of the exposed). Incident functional renal impairment (estimated glomerular filtration rate $\left.<60 \mathrm{ml} / \mathrm{min} / 1.73 \mathrm{~m}^{2}\right)$ was detected in 233 participants $(117(13 \%)$ of the unexposed and $116(11 \%)$ of the exposed). While 572 participants had at least one indicator of renal impairment (266 (29\%) of the unexposed and $306(29 \%)$ of the exposed), the presence of both indicators was detected in only 30 participants $(8$ $(0.9 \%)$ of the unexposed and $22(2.1 \%)$ of the exposed). The age and sex adjusted hazard ratio for microalbuminuria after acute gastroenteritis was 1.18 (0.97 to 1.44), and the age and sex adjusted hazard ratio for 


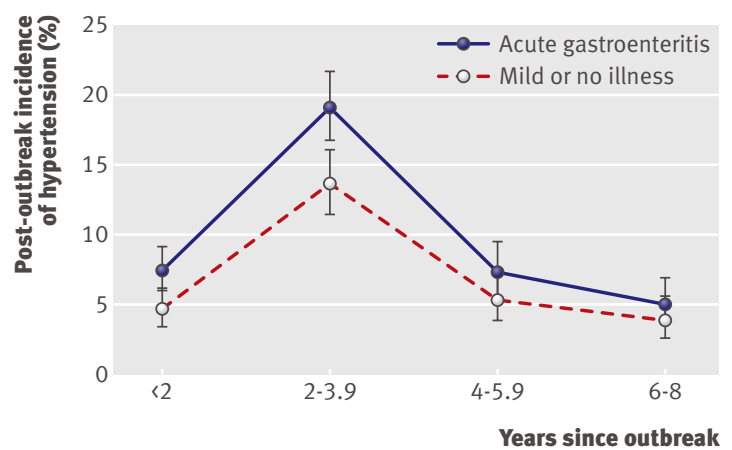

Fig 2 Incidence of hypertension, adjusted for age and sex, after outbreak of acute gastroenteritis from drinking water contaminated with E coli 0157:H7 and Campylobacter.

(Outbreak was in May 2000, and study enrolment began in 2002)

functional renal impairment was 1.13 (0.87 to 1.46 ). The age and sex adjusted hazard ratio for having either indicator was 1.15 (0.97 to 1.35$)$, but this increased to 3.41 (1.51 to 7.71 ) when both indicators were present. Controlling for potential confounders did not change the hazard ratios $(<5 \%)$ or the statistical significance. When participants with renal impairment at study entry were excluded, the hazard ratio for having either indicator decreased to 1.11 (0.91 to 1.35$)$, but the hazard ratio for having both indicators increased to 7.51 (1.69 to 33.43).

Significantly fewer assessments of structural and functional renal impairment occurred in the exposed group than in the unexposed group (mean number of assessments $4.5 v 4.7, \mathrm{P}=0.017$ ), and the age and sex adjusted hazard ratio for having either indicator of renal impairment was significantly modified by response pattern $(\mathrm{P}=0.008)$, ranging from 1.0 (0.80 to 1.24$)$ among committed responders to 2.1 (0.96 to 4.46) among early leavers. Similar modification was observed for the presence of both structural and functional renal impairment: the hazard ratio was substantially higher among participants with incomplete follow-up (hazard ratio 11.4 (1.4 to 93.2)) compared with committed responders (2.4 (1.0 to 5.9)) (a three-group comparison was not possible because of small cell sizes).

Risk of cardiovascular disease

Between 15 May 2000 and August 2008, 33 incident cardiovascular events were reported: 18 myocardial

Table 2 | Risk for hypertension among 1977 participants in Walkerton Health Study in relation to self reported acute gastroenteritis from drinking water contaminated with $E$ coli 0157:H7 and Campylobacter

\begin{tabular}{|c|c|c|c|c|}
\hline \multirow[b]{2}{*}{ Exposure } & \multirow{2}{*}{$\begin{array}{c}\text { No }(\%) \text { of cases } \\
\text { of incident } \\
\text { hypertension }\end{array}$} & \multirow[b]{2}{*}{$\begin{array}{l}\text { Median years } \\
\text { of follow-up* }\end{array}$} & \multicolumn{2}{|c|}{ Hazard ratio $(95 \% \mathrm{Cl})$} \\
\hline & & & $\begin{array}{l}\text { Age and sex } \\
\text { adjusted }\end{array}$ & $\begin{array}{c}\text { Multivariate } \\
\text { adjusted } \dagger\end{array}$ \\
\hline No illness or mild illness $(n=910)$ & $294(32)$ & 7.9 & 1.0 & 1.0 \\
\hline Acute gastroenteritis $(n=1067)$ & $403(38)$ & 7.9 & $1.43(1.23$ to 1.66$)$ & 1.33 (1.14 to 1.54$)$ \\
\hline
\end{tabular}

*Since outbreak (15 May 2000).

†Hazard ratios were estimated with Cox proportional hazard regression adjusted for age (in 1 year increments), sex, health assessment in year before outbreak, obesity at study entry (body mass index $\geq 30$ ), diabetes, tobacco smoking, and family history of hypertension. infarctions (including one death due to myocardial infarction), 15 strokes, and six congestive heart failures (events were not mutually exclusive). The first reported event occurred in November 2000. Figure 3 shows the number of cardiovascular events over time in the exposed and unexposed groups. Participants who reported a cardiovascular event were 2.6 times more likely to have persistent renal impairment $(\mathrm{P}=0.002)$. The multivariate adjusted hazard ratio for cardiovascular disease after acute gastroenteritis was 2.13 (1.03 to 4.43 ) (table 3).

Participants were not asked about the occurrence of cardiovascular events until the second year of the study. Therefore, the 228 participants lost to followup after the first study year were excluded from this analysis. However, they seemed to be at slightly lower risk for cardiovascular disease in that they were significantly less likely than those included in the analysis to have a family history of either hypertension $(32 \% v 40 \%)$ or diabetes (15\% v 24\%), and no differences were observed in body mass index, systolic blood pressure, or probability of exposure to acute gastroenteritis. The adjusted hazard ratio for cardiovascular disease did not vary significantly with response pattern $(\mathrm{P}=0.51)$, and it did not change after controlling for number of assessments.

\section{DISCUSSION}

To our knowledge, the Walkerton Health Study is the first to evaluate the long term health outcomes after gastroenteritis from drinking water contaminated with E coli O157:H7 and Campylobacter. Compared with participants who were not ill or only mildly ill during the outbreak, participants who experienced acute gastroenteritis were 1.3 times more likely to develop hypertension, 3.4 times more likely to develop both structural and functional renal impairment, and were 2.1 times more likely to report a physician diagnosis of a cardiovascular event. Although the risk for the outcome of any renal impairment was increased, the confidence interval bounded 1.00. In contrast, when we increased the specificity of the outcome to include the presence of both structural and functional renal impairment, the hazard ratio increased from 1.15 to 3.41 and was highly significant despite a dramatic reduction in the event rate (from 572 to 30). Recent research suggests that the presence of both structural and functional renal impairment is a stronger predictor of mortality, cardiovascular morbidity, and renal decline than either structural or functional renal impairment alone. ${ }^{293536}$

\section{Strengths and limitations of study}

The unique circumstances of this outbreak have allowed us to track the long term health effects of gastroenteritis from $E$ coli O157:H7 within a single cohort, which is normally not possible given the wide dispersal of $E$ coli O157:H7 outbreaks. ${ }^{72021}$ However, because this study originated in the context of an environmental disaster, there are several associated limitations. 


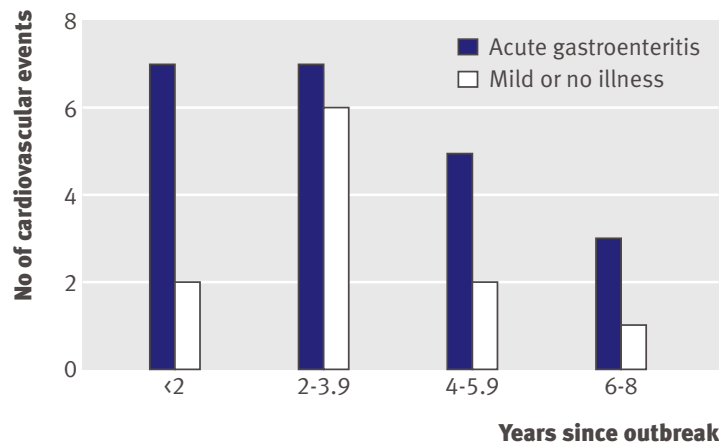

Fig 3 Self reported cardiovascular events after outbreak of acute gastroenteritis from drinking water contaminated with $E$ coli 0157:H7 and Campylobacter. (If multiple events were reported, only the first event was counted. Outbreak was in May 2000 , and study enrolment began in 2002)

\section{Recall bias}

The explosive onset and high frequency of gastroenteritis in a small rural community challenged the available medical resources, and, once the outbreak source and causative organisms were identified, adults were advised not to seek medical attention or submit stool samples. As a result, the severity of gastroenteritis at the time of the outbreak was largely determined by self report.

While inaccurate recall may attenuate any associations between exposure and outcome, recall bias among individuals who developed health conditions could falsely exaggerate effect measures. However, because hypertension and renal impairment were measured with standardised objective techniques and participants were not informed of any diagnoses until after survey completion, the effect of any recall bias would attenuate rather than inflate these associations. To reduce subjectivity in reporting cardiovascular disease, this outcome was based on a diagnosis made by a health professional. The sensitivity and specificity of self reported cardiovascular disease is good, with reported ranges of $66-90 \%$ and $98-99 \%$, respectively. ${ }^{37-39}$ Importantly, most of the self reported events that failed to meet the more stringent diagnostic criteria received related

Table 3|Risk for cardiovascular disease among 1749 participants in Walkerton Health Study in relation to self reported acute gastroenteritis from drinking water contaminated with $E$ coli 0157:H7 and Campylobacter

\begin{tabular}{|c|c|c|c|c|c|}
\hline \multirow[b]{2}{*}{ Exposure } & \multicolumn{3}{|c|}{$\begin{array}{c}\text { No (\%) of cases } \\
\text { of cardiovascular disease* }\end{array}$} & \multicolumn{2}{|c|}{ Hazard ratio $(95 \% \mathrm{CI})$} \\
\hline & $\begin{array}{l}\text { Myocardial } \\
\text { infarction }\end{array}$ & Stroke & $\begin{array}{l}\text { Congestive } \\
\text { heart failure }\end{array}$ & $\begin{array}{l}\text { Age and sex } \\
\text { adjusted }\end{array}$ & $\begin{array}{l}\text { Multivariate } \\
\text { adjusted } \dagger\end{array}$ \\
\hline $\begin{array}{l}\text { No illness or mild } \\
\text { illness }(n=812)\end{array}$ & $6(0.7)$ & $5(0.6)$ & $2(0.2)$ & 1.0 & 1.0 \\
\hline $\begin{array}{l}\text { Acute gastroenteritis } \\
(n=937)\end{array}$ & $12(1.3)$ & $10(1.1)$ & $4(0.4)$ & 2.24 (1.08 to 4.65$)$ & 2.13 (1.03 to 4.43$)$ \\
\hline \multicolumn{6}{|c|}{$\begin{array}{l}\text { *Cardiovascular disease is a composite of self reported physician diagnosis of myocardial infarction, } \\
\text { cerebrovascular events, and congestive heart failure. } \\
\text { †Hazard ratios were estimated with Cox proportional hazard regression adjusted for age (in } 1 \text { year increments), } \\
\text { sex, health assessment in year before outbreak, obesity at study entry (body mass index } \geq 30 \text { ), and tobacco } \\
\text { smoking. }\end{array}$} \\
\hline
\end{tabular}

diagnoses, including silent myocardial infarction and other coronary disease. ${ }^{3738}$

Further, to examine the potential for false reporting among the participants of the Walkerton Health Study, tinnitus was included as a self reported outcome since there is no biological reason to expect that tinnitus would result from the outbreak. ${ }^{25}$ If participants falsely reported or exaggerated the severity of illness at the time of the outbreak and falsely reported experiencing health outcomes, a spurious association between gastroenteritis and tinnitus would be observed. However the observed relative risk for tinnitus from gastroenteritis was $1.1(\mathrm{P}=0.6)$. The absence of an association between the exposure and tinnitus increases our confidence in the validity of self reported outcomes such as cardiovascular disease.

Finally, defining exposure based on confirmation from health records did not substantively change effect sizes between exposure and hypertension, renal impairment, and cardiovascular disease. The similarity of these results suggests that any effect of recall bias was minimal.

\section{Confounding}

Although adults who developed acute gastroenteritis during the outbreak had more risk factors than those who did not experience acute gastroenteritis, we used several methods to control for confounding - exclusion, restriction, and statistical adjustment. Firstly, participants with self reported or medically documented evidence of pre-outbreak hypertension, renal impairment, diabetes, cardiovascular disease, or chronic gastrointestinal illness were excluded from this study. Although residual confounding is always a concern, for an unmeasured confounder to affect an association substantively, it must be highly prevalent and strongly associated with both the exposure and the outcome. ${ }^{4041}$ Given the likelihood that any unmeasured confounder would be highly correlated with the measured confounders, the impact of any residual confounding from unmeasured covariates would be minimal. ${ }^{42}$

Further, recognising that conditions such as hypertension and renal impairment are asymptomatic and that diagnosis may not occur in the absence of active surveillance, we were concerned about the potential for misclassifying prevalent cases as incident. As evident in fig 2, a sharp peak in the incidence of hypertension was observed in both exposure groups between two and four years after the outbreak-which coincided with the start of study enrolment in 2002, when blood pressure monitoring began - and is almost certainly due to the detection of previously undiagnosed hypertension. Restricting the analysis to eliminate possibly prevalent cases of hypertension and renal impairment produced stronger associations with exposure, suggesting that the overall associations may in fact be attenuated by the presence of prevalent cases.

\section{Loss to follow-up}

Loss to follow-up is a potential source of bias in longitudinal studies. Although there was no significant 
difference between the exposure groups in the overall number of follow-up visits or the years of follow-up from the time of the outbreak, the unexposed group received significantly more assessments for renal impairment, which could potentially attenuate the hazard ratio for this outcome because of differential information bias in favour of the unexposed. Our assessment of the direction and size of potential bias from loss to follow-up suggests minimal bias on the associations with hypertension and cardiovascular disease. The hazard ratios for renal impairment, however, were significantly elevated among participants with incomplete follow-up, possibly because of referral to specialist care after diagnosis of renal impairment. Participants lost to follow-up did not seem to have more risk factors (data not shown), but, as part of the study mandate, hypertensive participants were treated with renal protective agents (angiotensin converting enzyme inhibitors or angiotensin receptor blockers), which may have slowed the progression of renal disease in participants who remained in the study to receive treatment.

\section{Coinfection}

Although $E$ coli $\mathrm{O} 157: \mathrm{H} 7$ was the primary bacteria isolated in the contaminated drinking water source, Campylobacter (a bacterium only rarely associated with renal sequelae) was also present, and there was evidence of coinfection in some stool cultures. Biological experiments and human observational studies emphasise the risk of long term renal sequelae after recovery from haemolytic-uraemic syndrome, the most toxic form of acute $E$ coli $\mathrm{O} 157: \mathrm{H} 7$ infection. ${ }^{194344}$ In the current study, we examined the incidence of long term sequelae after acute gastroenteritis, which in some participants could be the result of subclinical or unrecognised haemolytic-uraemic syndrome. ${ }^{45}$

Of those tested, 19\% were positive for E coli O157:H7, which is consistent with that reported in smaller outbreaks where most of the affected are tested $(17 \%-45 \%) .{ }^{4647}$ Even had more specimens been tested in our study, stool cultures can lack sensitivity, and negative results do not always exclude infection, particularly in the context of a large outbreak when samples cannot be analysed promptly. ${ }^{4849}$ Furthermore, some Walkerton residents required a negative stool sample test to return to work, and so these tests were often performed to confirm the absence rather than presence of disease and many were conducted after the period of shedding had stopped.

The implications of a mixed bacterial load would be to attenuate the specific nephrotoxic effect of $E$ coli O157:H7. It is important to note, however, that the infectious dose of $E$ coli O157:H7 is much lower than Campylobacter, requiring only 10 organisms to cause infection, ${ }^{50}$ as compared with $400-500$ bacteria in the case of Campylobacter. ${ }^{51}$ Thus, the probability that a participant with acute gastroenteritis was not exposed to $E$ coli $\mathrm{O} 157: \mathrm{H} 7$ is small, and the effect of such misclassification would be in the direction of the null hypothesis. Among the group of participants who did not meet the criteria for acute gastroenteritis, 15\% had mild diarrhoeal illness. Including those with mild diarrhoea in the acutely ill group resulted in slightly attenuated associations between exposure and each of the outcomes (hazard ratios for hypertension $1.33 v 1.17$, renal impairment $3.41 v 2.72$, and cardiovascular disease 2.13 v 2.06).

\section{Comparison with other studies}

An analysis of the risk of renal impairment and hypertension in children suggested that acute gastroenteritis did not produce adverse long term sequelae in those younger than 18 years at the time of the Walkerton outbreak. ${ }^{52}$ One possible explanation for the difference in outcomes between adults and children is that medical attention was focused on children at the time of the outbreak, and more adults than children could have developed unrecognised haemolytic-uraemic syndrome, which could be associated with more long term renal sequelae. It is also conceivable that children, unlike adults, have more renal reserve and are better able to recover from an insult of $E$ coli O157:H7 Shiga toxin. Reports indicate that exposure to E coli O157:H7 may cause a spectrum of endothelial dysfunction due to microthrombotic and inflammatory events resulting from incomplete to overt microangiopathy (haemolytic-uraemic syndrome). This sick vessel syndrome or cardiovascular continuum of risk due to a spill-over of inflammatory cytokines and microthrombotic growth factors may explain the increased number of cardiovascular events in those who developed acute gastroenteritis during the outbreak. ${ }^{1853-55}$ Although these findings are provocative, a more accurate assessment of cardiovascular risk can be obtained only by linkage of survey data to medical records.

\section{Conclusion}

Acute gastroenteritis from drinking water contaminated with E coli O157:H7 and Campylobacter was associated with an increased risk for hypertension, renal impairment, and self reported cardiovascular disease. This study represents a rare opportunity to assess the long term sequelae after acute gastroenteritis from drinking bacterially contaminated water. Our findings underline the need for following up individual cases of food or water poisoning by $E$ coli $\mathrm{O} 157: \mathrm{H} 7$ to prevent or reduce silent progressive vascular injury. Hypertension is the most common treatable risk factor for cardiovascular disease, ${ }^{56}$ and, given the silent nature of hypertension and renal impairment, annual blood pressure monitoring and periodic monitoring of renal function may be warranted for individuals who experience acute gastroenteritis after exposure to food or water contaminated with $E$ coli O157:H7. These long term consequences emphasise the importance of ensuring safe food and water supply as a cornerstone of public health. 


\section{WHAT IS ALREADY KNOWN ON THIS TOPIC}

Escherichia coli 0157:H7 infections cause 50 000-120 000 gastroenteric illnesses annually in the United States, resulting in over 2000 hospitalisations and 60 deaths

Exposure to $E$ coli 0157:H7 Shiga toxins can cause both renal and vascular injury resulting in haemolytic-uraemic syndrome

The long term health effects of haemolytic-uraemic syndrome from exposure to $E$ coli 0157:H7 in children are well documented, but the long term health effects of milder exposure in symptomatic adults are largely unknown

\section{WHAT THIS STUDY ADDS}

Acute gastroenteritis in adults from drinking water contaminated with E coli 0157:H7 and Campylobacter was associated with an increased risk of hypertension, renal impairment, and cardiovascular disease

Symptomatic cases of food or water poisoning by $E$ coli $0157: \mathrm{H} 7$ require following up to prevent or reduce silent progressive vascular injury: annual monitoring of blood pressure and periodic monitoring of renal function may be warranted

We thank the participants of the Walkerton Health Study, who have freely given of themselves to participate over an extended period after tragic circumstances. We also thank Ms Arlene Richards and the staff of the Walkerton Health Study for their efforts in ensuring accurate and timely data collection.

Contributors: All authors participated in the conception and design of the study and in the critical revision of the manuscript for important intellectual content. WFC, MS, and AXG obtained funding for the study. WFC, JJM, MS, LM, RS, and AXG participated in data acquisition. JMS and JJM performed the data analysis. WFC, JMS, JJM, LM, and AXG interpreted the data. WFC, JMS, JJM produced the draft of the manuscript. All authors had full access to all of the data (including statistical reports and tables) in the study and can take responsibility for the integrity of the data and the accuracy of the data analysis. WFC is guarantor for the study. Funding: This study was funded by the Ontario Ministry of Health and Long term Care, which had no role in design and conduct of the study; collection, analysis, and interpretation of the data; or preparation, review, or approval of the manuscript.

Competing interests: All authors have completed the Unified Competing Interest form at http://www.icmje.org/coi_disclosure.pdf (available on request from the corresponding author) and declare that (1) no authors have received support from any companies for the submitted work; (2) no authors have any relationships with any companies that might have an interest in the submitted work in the previous 3 years; (3) their spouses, partners, or children have no financial relationships that may be relevant to the submitted work; and (4) no authors have non-financial interests that may be relevant to the submitted work.

Ethical approval: Participants provided written informed consent, and ethical approval was obtained from the University of Western Ontario's Research Ethics Board for Health Sciences.

Data sharing: The technical appendix, statistical code, and dataset are available from the corresponding author, William.Clark@lhsc.on.ca

1 Riley LW, Remis RS, Helgerson SD, McGee HB, Wells JG, David BR, et al. Hemorrhagic colitis associated with a rare Escherichia coli serotype. N Engl I Med 1983;308:681-5.

2 Dundas S, Todd WT, Stewart Al, Murdoch PS, Chaudhuri AK, Hutchinson SJ. The central Scotland Escherichia coli 0157:H7 outbreak: risk factors for the hemolytic uremic syndrome and death among hospitalized patients. Clin Infect Dis 2001;33:923-31.

3 Michino H, Araki K, Minami S, Takaya S, Sakai N, Miyazaki M, et al. Massive outbreak of Escherichia coli 0157:H7 infection in schoolchildren in Sakai City, Japan, associated with consumption of white radish sprouts. Am J Epidemiol 1999;150:787-96.

4 Whittaker PJ, Sopwith W, Quigley C, Gillespie I, Willshaw GA, Lycett C, et al. A national outbreak of verotoxin-producing Escherichia coli 0157 associated with consumption of lemon-and-coriander chicken wraps from a supermarket chain. Epidemiol Infect 2009;137:375-82.

5 Leotta G, Miliwebsky E, Chinen I, Espinosa EM, Azzopardi K, Tennant SM, et al. Characterisation of Shiga toxin-producing Escherichia coli 0157 strains isolated from humans in Argentina, Australia and New Zealand. BMC Microbiology 2008;8:46.
6 Powell M, Ebel E, Schlosser W. Considering uncertainty in comparin the burden of illness due to foodborne microbial pathogens. Int J Food Microbiol 2001;69:209-15.

7 Wendel AM, Johnson DH, Sharapov U, Grant J, Archer JR, Monson T, et al. Multistate outbreak of Escherichia coli 0157:H7 infection associated with consumption of packaged spinach, AugustSeptember 2006: the Wisconsin investigation. Clin Infect Dis 2009;48:1079-86.

8 Sehgal R, Kumar Y, Kumar S. Prevalence and geographical distribution of Escherichia coli 0157 in India: a 10-year survey. Tran R Soc Trop Med Hyg 2008;102:380-3.

9 Effler E, Isaacson M, Arntzen L, Heenan R, Canter P, Barrett T, et al. Factors contributing to the emergence of Escherichia coli 0157 in Africa. Emerg Infect Dis 2001;7:812-9.

10 Hamner S, Broadaway SC, Mishra VB, Tripathi A, Mishra RK, Pulcini E, et al. Isolation of potentially pathogenic Escherichia coli 0157:H7 from the Ganges River. Appl Environ Microbiol 2007;73:2369-72.

11 Germani Y, Soro B, Vohito M, Morel O, Morvan J. Enterohaemorrhagic Escherichia coli in Central African Republic. Lancet 1997;349:1670.

12 Frenzen PD, Drake A, Angulo FJ. Economic cost of illness due to Escherichia coli 0157 infections in the United States. J Food Prot 2005;68:2623-30.

13 Mead PS, Slutsker L, Dietz V, McCraig LF, Bresee JS, Shapiro C, et al. Food-related illness and death in the United States. Emerg Infect Dis 2000;5:607-25.

14 Tarr PI. Basic fibroblast growth factor and Shiga toxin-0157:H7associated hemolytic uremic syndrome. J Am Soc Nephrol 2002;13:817-20.

15 Brenner BM, Lawler EV, Mackenzie HS. The hyperfiltration theory: a paradigm shift in nephrology. Kidney Int 1996;49:1774-7.

16 Ohmi K, Kiyokawa N, Takeda T, Fujimoto J. Human microvascular endothelial cells are strongly sensitive to Shiga toxins. Biochem Biophys Res Commun 1998;251:137-41.

17 Bonetti PO, Lerman LO, Lerman A. Endothelial dysfunction: a marker of atherosclerotic risk. Arterioscler Thromb Vasc Biol 2003;23:168-75.

18 Hirsch AT, Folsom AR. The continuum of risk: vascular pathophysiology, function, and structure. Circulation 2004;110:2774-7.

19 Garg AX, Suri RS, Barrowman N, Rehman F, Matsell D, Rosas-Arellano MP, et al. Long-term renal prognosis of diarrheaassociated hemolytic uremic syndrome: a systematic review, metaanalysis, and meta-regression. JAMA 2003;290:1360-70.

20 Su C, Brandt LI. Escherichia coli 0157: H7 infection in humans. Ann Intern Med 1995;123:698-707.

21 Rangel JM, Sparling PH, Crowe C, Griffin PM, Swerdlow DL. Epidemiology of Escherichia coli 0157:H7 outbreaks, United States, 1982-2002. Emerg Infect Dis 2005;11:603-9.

22 Salvadori M, Sontrop JM, Garg AX, Moist L, Suri R, Clark WF. Factors that led to the Walkerton tragedy. Kidney Int 2009;75:S33-4.

23 Garg AX, Moist L, Matsell D, Thiessen-Philbrook HR, Haynes RB, Suri RS, et al. Risk of hypertension and reduced kidney function afte acute gastroenteritis from bacteria-contaminated drinking water. CMAI 2005;173:261-8.

24 Garg AX, Macnab J, Clark W, Ray JG, Marshall JK, Suri RS, et al. Long term health sequelae following E. coli and Campylobacter contamination of municipal water. Population sampling and assessing non-participation biases. Can J Public Health 2005;96:125-30.

25 Garg AX, Marshall J, Salvadori M, Thiessen-Philbrook HR, Macnab J, Suri RS, et al. A gradient of acute gastroenteritis was characterized, to assess risk of long-term health sequelae after drinking bacterialcontaminated water. / Clin Epidemiol 2006;59:421-8.

26 Chobanian AV, Bakris GL, Black HR, Cushman WC, Green LA, Izzo JL Jr et al. Seventh report of the Joint National Committee on Prevention, Detection, Evaluation, and Treatment of High Blood Pressure. Hypertension 2003;42:1206-52.

27 Levey AS, Greene T, Kusek JW, Beck GJ. A simplified equation to predict glomerular filtration rate from serum creatinine. J Am Soc Nephrol 2000;11:155A.

28 Vassalotti JA, Stevens LA, Levey AS. Testing for chronic kidney disease: a position statement from the National Kidney Foundation. Am J Kidney Dis 2007;50:169-80.

29 Hallan SI, Ritz E, Lydersen S, Romundstad S, Kvenild K, Orth SR. Combining GFR and albuminuria to classify CKD improves prediction of ESRD. J Am Soc Nephrol 2009;20:1069-77.

30 Expert Committee on the Diagnosis and Classification of Diabetes Mellitus. Report of the Expert Committee on the Diagnosis and Classification of Diabetes Mellitus. Diabetes Care 2003;261:5-20S.

31 Kleinbaum DG, Klein M. Evaluating the proportional hazards assumption. In: Kleinbaum DG, Klein M, Survival analysis. 2nd ed. Springer, 2005:131-71.

32 Mickey RM, Greenland S. The impact of confounder selection criteria on effect estimation. Am J Epidemiol 1989;129:125-37. 
33 Maldonado G, Greenland S. Simulation study of confounderselection strategies. Am J Epidemiol 1993;138:923-36.

34 Greenland S, Rothman K. Introduction to stratified analysis. In: Rothman K, Greenland S, eds. Modern epidemiology. 2nd ed. Lippincott-Raven, 1998:253-79.

35 Halbesma N, Kuiken DS, Brantsma AH, Bakker SJ, Wetzels JF, De Zeeuw D, et al. Macroalbuminuria is a better risk marker than low estimated GFR to identify individuals at risk for accelerated GFR loss in population screening. J Am Soc Nephrol 2006;17:2582-90.

36 Hemmelgarn B, Manns B, Lloyd A, James MT, Klarenbach S, Quinn RR, et al. Relation between kidney function, proteinuria, and adverse outcomes. JAMA 2010;303:423-9.

37 Engstad T, Bonaa KH, Viitanen M. Validity of self-reported stroke: the Tromso Study. Stroke 2000;31:1602-7.

38 Colditz GA, Martin P, Stampfer MJ, Willett WC, Sampson L, Rosner B, et al. Validation of questionnaire information on risk factors and disease outcomes in a prospective cohort study of women. Am J Epidemiol 1986;123:894-900.

39 Okura Y, Urban LH, Mahoney DW, Jacobsen SJ, Rodeheffer RJ. Agreement between self-report questionnaires and medical record data was substantial for diabetes, hypertension, myocardial infarction and stroke but not for heart failure. J Clin Epidemiol 2004;57:1096-103.

40 Breslow NE, Day NE, Gart JJ, Esteve J, Benhamou E, Raymond L. Statistical methods in cancer research. International Agency for Research on Cancer, 1980.

41 Groenwold RH, Nelson DB, Nichol KL, Hoes AW, Hak E. Sensitivity analyses to estimate the potential impact of unmeasured confounding in causal research. Int I Epidemiol 2010;39:107-17.

42 Blair A, Stewart P, Lubin JH, Forastiere F. Methodological issues regarding confounding and exposure misclassification in epidemiological studies of occupational exposures. Am J Ind Med 2007;50:199-207.

43 Karmali MA, Petric M, Lim C, Fleming PC, Arbus GS, Lior H. The association between idiopathic hemolytic uremic syndrome and infection by verotoxin-producing Escherichia coli. J Infect Dis 1985;151:775-82.

44 Petruzziello TN, Mawji IA, Khan M, Marsden PA. Verotoxin biology: molecular events in vascular endothelial injury. Kidney Int 2009;75:S17-19.
45 Karmali MA. Host and pathogen determinants of verocytotoxin producing Escherichia coli-associated hemolytic uremic syndrome. Kidney Int 2009;75:S4-7.

46 Olsen SJ, Miller G, Breuer T, Kennedy M, Higgins C, Walford J, et al. A waterborne outbreak of Escherichia coli 0157:H7 infections and hemolytic uremic syndrome: implications for rural water systems. Emerg Infect Dis 2002;8:370-5.

47 Centers for Disease Control and Prevention. Outbreak of Escherichia coli 0157:H7 and Campylobacter among attendees of the Washington County Fair-New York, 1999. MMWR Morb Mortal Wkly Rep 1999;48:803-5.

48 Tarr PI, Neill MA, Clausen CR, Watkins SL, Christie DL, Hickman RO. Escherichia coli 0157:H7 and the hemolytic uremic syndrome: importance of early cultures in establishing the etiology. J Infect Dis 1990;162:553-6.

49 Kehl SC. Role of the laboratory in the diagnosis of enterohemorrhagic Escherichia coli infections. J Clin Microbiol 2002;40:2711-5.

50 US Food and Drug Administration. BBB-Escherichia coli 0157:H7 (EHEC). 2009. www.fda.gov/food/foodsafety/foodborneillness/ foodborneillnessfoodbornepathogensnaturaltoxins/badbugbook/ ucm071284.htm.

51 Food and Drug Administration. BBB-Campylobacter jejuni. 2009. www.fda.gov/food/foodsafety/foodborneillness/ foodborneillnessfoodbornepathogensnaturaltoxins/badbugbook/ ucm070024.htm.

52 Garg AX, Clark WF, Salvadori M, Thiessen-Philbrook HR, Matsell D. Absence of renal sequelae after childhood Escherichia coli 0157: H7 gastroenteritis. Kidney Int 2006;70:807-12.

53 Ross R. Atherosclerosis-an inflammatory disease. N Engl/ Med 1999;340:115-26.

54 Ridker PM, Hennekens CH, Buring JE, Rifai N. C-reactive protein and other markers of inflammation in the prediction of cardiovascular disease in women. N Engl J Med 2000;342:836-43.

55 Dzau VJ. Markers of malign across the cardiovascular continuum: interpretation and application. Circulation 2004;109:IV1-2.

56 Wolf-Maier K, Cooper RS, Banegas JR, Giampaoli S, Hense HW, Joffres $M$, et al. Hypertension prevalence and blood pressure levels in 6 European countries, Canada, and the United States. JAMA 2003;289:2363-9.

Accepted: 8 September 2010 